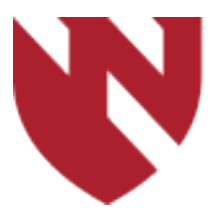

December 2020

\title{
Internet Transparency of Local Men's Health Clinics in Nebraska
}

Jinfeng Jiang

University of Nebraska Medical Center

Jordan Stegman

University of Nebraska Medical Center

Christopher M. Deibert

University of Nebraska Medical Center

Tell us how you used this information in this short survey.

Follow this and additional works at: https://digitalcommons.unmc.edu/gmerj

Part of the Advertising and Promotion Management Commons, Hormones, Hormone Substitutes, and Hormone Antagonists Commons, and the Urology Commons

\section{Recommended Citation}

Jiang, J., Stegman, J., , Deibert, C. M. Internet Transparency of Local Men's Health Clinics in Nebraska. Graduate Medical Education Research Journal. 2020 Dec 09; 2(2).

https://digitalcommons.unmc.edu/gmerj/vol2/iss2/4

This Original Report is brought to you for free and open access by DigitalCommons@UNMC. It has been accepted for inclusion in Graduate Medical Education Research Journal by an authorized editor of DigitalCommons@UNMC. For more information, please contact digitalcommons@unmc.edu. 


\title{
Internet Transparency of Local Men's Health Clinics in Nebraska
}

\author{
Abstract \\ An overview of Men's Health Clinics offering Testosterone Therapy in a Midwest State. \\ Introduction/ Background - Since 2001, there has been a 300\% increase in the use of Testosterone \\ therapy. However, there remains limited published data on the demographics of facilities and providers \\ that advertise this service. This study aims to look at such demographics of advertised Men's health \\ clinics in Nebraska. \\ Methods/ Materials - An internet search was conducted with the phrases "Nebraska Male health clinics, \\ Nebraska Low T/testosterone, Nebraska Hormone Replacement Therapy". All clinics that were found \\ offering Testosterone therapy with Men's health in their mission statement were included. Data was \\ gathered using 6 questions, with answers obtained from the public website or by calling the office. \\ Results - 19 different facilities were found that self-identified as Men's Health clinics. 5/19 facilities were \\ nationally corporate owned, $13 / 19$ were individually owned, and 1 was an academic university. All offered \\ Testosterone Therapy. Of the 19 facilities, 10/19 branded themselves primarily as Men's Health Clinics. 6/ \\ 10 out of those offered testosterone therapy, Plasma infusion, and Penile Shockwave Therapy. Those that \\ offered services other than Men's health were marketed as Medical Spas and Aesthetic centers, offering \\ hormone replacement therapy, aesthetics, and anti-aging treatments. 10/19 Clinics had no MD listed and \\ visits would be with a mid-level provider (NP or PA). Only 1/19 provided prices online, others required \\ consultation before prices would be given. Of the 19 facilities, only 6 accept insurance and the rest are \\ cash-pay clinics only. \\ Conclusions - Of the Nebraska clinics that self-identify as men's health clinics, many are individually \\ owned clinics with a focus on hormone replacement or aesthetics. Of those clinics, many were run \\ entirely by mid-levels or with a supervising MD overseeing mid-levels. Less than $1 / 3 r d$ of facilities accept \\ insurance and there is a lack of price transparency.
}

\section{Keywords}

Testosterone, TRT, Testosterone replacement therapy, Urology, Men's Health, Men's Health Clinic, Male Health Clinic

\section{Creative Commons License}

\section{(c) $($ ) $(9)$}

This work is licensed under a Creative Commons Attribution-Noncommercial-No Derivative Works 4.0 License. 
Internet Transparency of Local Men's Health Clinics

Jinfeng Jiang ${ }^{1}$, Jordan Stegman ${ }^{2}$, Christopher M. Deibert ${ }^{2}$

${ }^{1}$ University of Nebraska Medical Center, College of Medicine, Omaha, NE

${ }^{2}$ University of Nebraska Medical Center, Division of Urological Surgery, Omaha, NE

\section{Abstract}

Introduction: Since 2001, there has been a $300 \%$ increase in the use of testosterone therapy. However, there remains limited published data on the organizational structure of the facilities and demographics of the providers that offer this service. This study aims to look at the structure and provider demographics of advertised men's health clinics in Nebraska.

Methods: An internet search was conducted with the phrases "Nebraska male health clinics, Nebraska low T/testosterone, Nebraska hormone replacement therapy." All clinics that were found offering testosterone therapy with men's health in their mission statement were included. Data were gathered using six questions, with answers obtained from the public website or by calling the office.

Results: Nineteen different facilities were found that self-identified as men's health clinics. Five out of the nineteen facilities were owned by national corporate entities, 13/19 were individually owned, and one was located at an academic university. All facilities offered testosterone therapy. Of the 19 facilities, $10 / 19$ branded themselves primarily as men's health clinics of which six offered testosterone therapy, plasma infusion, and penile shockwave therapy. Ten out of the 19 clinics had no MD listed and visits were with an advanced practice provider (NP or PA). Only $1 / 19$ provided prices online; whereas, others required consultation before prices would be given. Of the 19 facilities, only six accepted insurance.

Conclusions: Of the Nebraska clinics that self-identify as men's health clinics, many are individually owned clinics. Of those clinics, over half were run entirely by advanced practice providers or with a supervising MD overseeing them. Less than one-third of facilities accept insurance and there is a lack of price transparency.

\section{Introduction}

Hypogonadism is a clinical condition defined as low levels of serum testosterone associated with specific signs and symptoms. ${ }^{1}$ When hypogonadism occurs in an older male, the condition is termed late onset hypogonadism (LOH). Common symptoms include decreased muscle mass and strength, increase in central body fat, loss of libido, memory loss, and difficulty in concentration. However, these symptoms can be hard to differentiate from regular aging associated symptoms. The American Urological Association guideline states that clinical hypogonadism is defined as serum testosterone levels lower than 300ng/ $\mathrm{dl}$ and treatment is clinically appropriate for any levels below this threshold. ${ }^{2}$ Treatment is in the form of prescription testosterone therapy (TTh), where extraneous testosterone hormone is introduced to the body to raise serum testosterone to a recommended level. ${ }^{3}$ Current methods include intradermal injections, transdermal patches, sub dermal pellets, or nasal application.

Prescription TTh remains a prevalent topic of discussion throughout the world. In the United States, the general public is exposed to an array of radio, television and internet advertisements, which is likely the major factor contributing to the $300 \%$ increase in testosterone use in men from 2002 to 2013. ${ }^{4}$ Studies have shown that this increase in prescribing has been accompanied by increases in testosterone level testing, prescriptions of testosterone without the full diagnostic evaluation recommended by clinical practice guidelines and use of testosterone for unproven conditions. ${ }^{5}$ Hundreds of men's health clinics have opened to accompany this trend, marketing themselves in several ways to appeal to consumers. ${ }^{6}$ Alongside TTh, many of these clinics offer experimental non-FDA approved therapies such as penile shockwave therapy and plasma infusion, with claims they boost sexual libido and overall well-being. These experimental therapies have not been studied rigorously and there is no scientific literature proving their efficacy. ${ }^{7}$

Patients increasingly rely on the internet to answer their health-related questions. ${ }^{8}$ In addition, small studies reveal that people generally consider attributes such as professional design, ease of use and scientific touch when assessing the credibility of medical information online, and disregard disclaimers and disclosure statements. ${ }^{9}$ The increase in use of the internet by the public, along with the potentially poor ability to distinguish between credible and misleading information underscores the need for more rigorous research surrounding how online marketing may impact the patient's view on health-related matters.
We conducted an exploratory study to determine what information is available online for patients seeking treatment at a men's health clinic in Nebraska. To our knowledge, no previous studies have been performed that evaluate the structure of men's health clinics, or demographics of providers working in these clinics. We also sought to determine the types of providers and therapies offered in these clinics.

\section{Methods}

We identified men's health clinics in the State of Nebraska using Google incognito internet search with the phrases "Nebraska male health clinics, Nebraska Low T/ testosterone, Nebraska Hormone Replacement Therapy." All clinics that were found offering testosterone therapy were reviewed. Data were gathered using six predetermined domains, with answers obtained from the public website or by calling the clinic directly for any information not available online. Transparency was measured by whether the information was publicly available online or over the phone. Clinics with multiple locations were treated as a single clinic for the analysis.

\section{Results}

Nineteen different facilities were found that self-identified as men's health clinics. Of these $5 / 19$ facilities were owned by national corporate entities, 13/19 were individually owned, and 1 was located at an academic university (our own institution) (Figure 1). On their websites, 19/19 listed services provided, 17/19 listed providers, and 1/19 listed prices for treatment. All of the identified men's health clinics offered Testosterone Replacement Therapy. Of the 19 facilities, $10 / 19$ branded themselves primarily as men's health clinics of which six offered testosterone therapy, plasma infusion for erectile dysfunction, and penile shockwave therapy (Figure 2). Those that offered services other than Men's health were marketed as medical spas and aesthetic centers, offering hormone replacement therapy, aesthetics, and anti-aging treatments. Regarding provider workforce, 10/19 clinics had no physician listed and visits were with an advance practice provider (NP or PA) (Figure 3). Seventeen of the 19 clinics listed provider qualifications on the website and the other two clinics were 
transparent of provider qualifications over the phone. Only $1 / 19$ provided prices online while the others required consultation before prices would be given. Information about insurance was posted online for $13 / 19$ clinics. Of the 19 facilities, only six accepted insurance and the rest are cash-pay clinics only.

\section{Discussion}

Since, the early 2000's, there has been a dramatic increase in testosterone prescription for TTh. In the decade from 2001 through 2011 , testosterone prescriptions tripled from $0.81 \%$ to $2.91 \%$ of all men over 40 , of which many did not have a clear clinical reason. ${ }^{1,6}$ Studies have shown that the major reasons for the increase is due to Direct to consumer advertising and non-FDA approved Late Onset Hypogonadism (LOH), which lacks clinical evidence. $^{10}$

Of the facilities offering testosterone therapy in Nebraska, we found the majority were clinics branded as Men's testosterone clinics or Men's health clinics with a primary focus on hormone replacement therapy and the rest as aesthetic centers or medical spas. Of these facilities, 13/19 were individual private clinics with only 1 academic center found to offer TTh. Many of the facilities were staffed primarily with advanced practice providers such as NPs or PAs with or without a supervising physician. All were very transparent about provider qualifications.

We also found that there exists a lack of price transparency for services offered by most clinics. Only $1 / 19$ of the facilities had prices listed on their website. The other clinics had no prices listed on their website and declined to provide price of treatment over the phone. Other reviews of Male clinics have found that costs for TTh can be up to $\$ 400$ monthly. ${ }^{12}$ In addition, two-thirds of the facilities are cashpay only, with no price transparency until after the initial exam and testing. In a study of primary care clinics, $60 \%$ provided cost estimates of the initial visit, showing that it is possible to provide this to interested patients. ${ }^{13}$ The out of pocket financial costs of TTh can be significant, but there exists a lack of data on safety and efficacy of male health clinics. The main concern with centers that monetize TTh is whether they are listening to the entirety of the patient's symptoms, discussing lifestyle modifications, and properly treating the patient's condition. Previous studies of TTh clinic websites have shown that they promote the benefits of TTh while neglecting to mention the risks. ${ }^{14}$

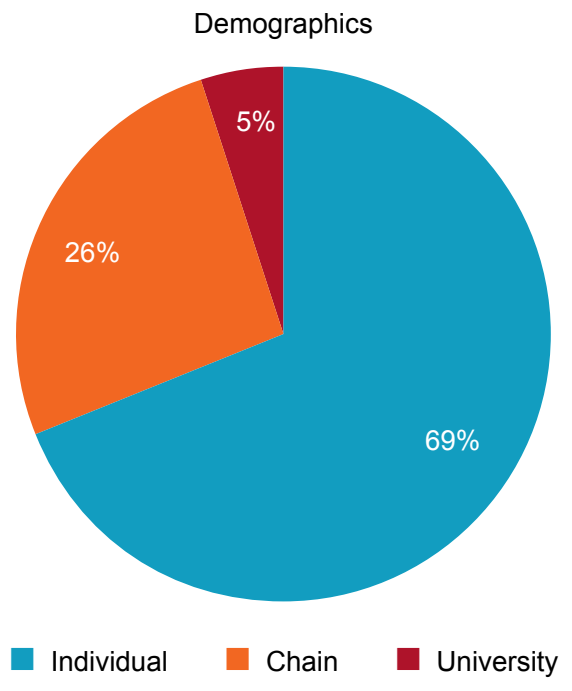

Figure 1. Ownership demographics of men's health clinics in Nebraska.

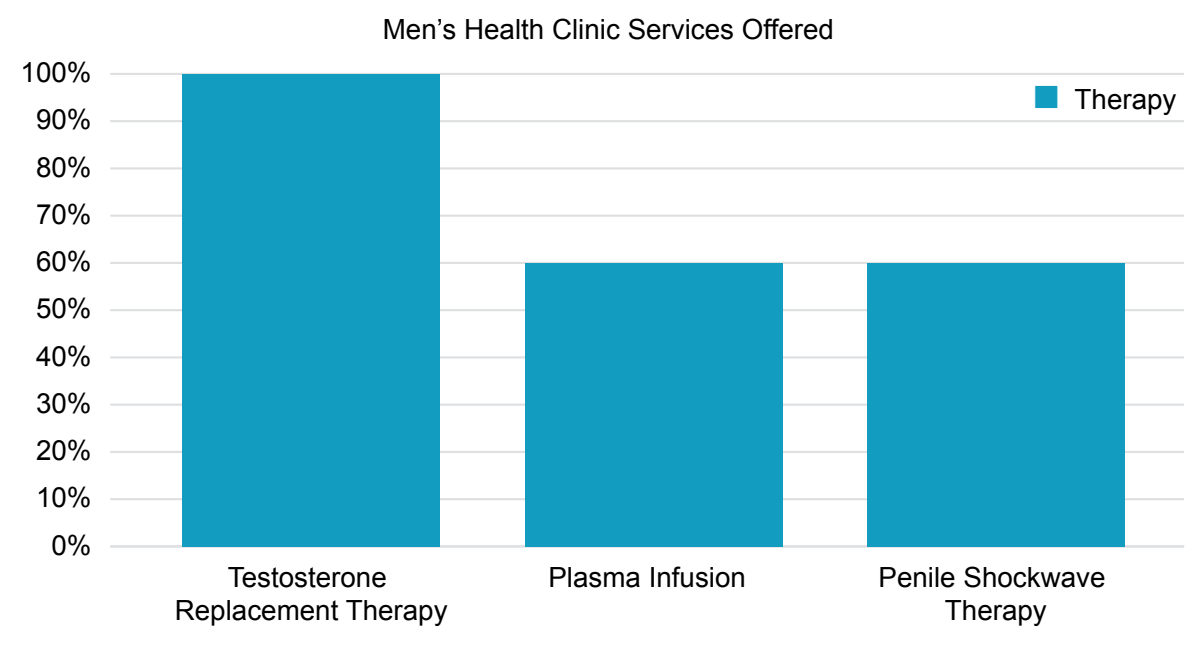

Figure 2. Treatments offered by men's health clinics in Nebraska.

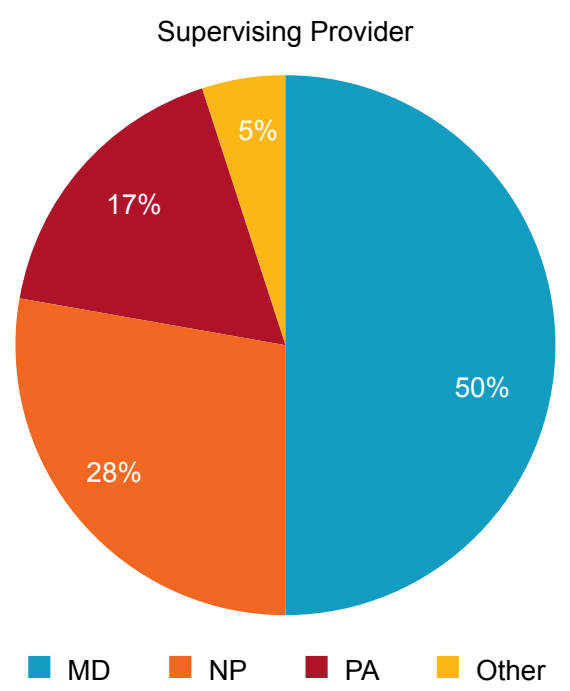

Figure 3. Degree of the medical provider at the men's health clinic. 
The American Urological Association currently defines hypogonadism as testosterone $<300 \mathrm{ng} / \mathrm{dl}$. They recommend treating hypogonadism until serum testosterone is in the range of 450-600 ng/dl, but many clinics advertise recommend raising testosterone levels to much higher levels. ${ }^{15}$ In 2014, The FDA added a black box warning of cardiovascular risks with TTh and rebranded the indication to pathological hypogonadism in an effort to prevent unnecessary prescribing, which led to a decrease in testosterone prescription from $2013-2016$. Unfortunately, it appears that many clinics are still using the FDA off-label Late Onset Hypogonadism (LOH) as justification for TTh. ${ }^{16}$ Many of the male health clinics are also advertising on their websites nonFDA approved plasma infusion and penile shockwave therapy, which has no clinical evidence to demonstrate its efficacy. The Sexual Medicine Society of North America considers these experimental therapies and should be restricted to clinical trial research. ${ }^{17}$

\section{References}

1 Nieschlag E, Swerdloff R, Behre HM, et al. Investigation, treatment and monitoring of late-onset hypogonadism in males. Aging Male. 2005;8:56-58.

2 Shin, Y. S., \& Park, J. K. (2019). The Optimal Indication for Testosterone Replacement Therapy in Late Onset Hypogonadism. Journal of clinical medicine, $8(2), 209$. https://doi.org/10.3390/ jcm8020209

3 Kumar P., Kumar N., Thakur D.S., Patidar A. Male hypogonadism: Symptoms and treatment. J. Adv. Pharm. Technol. Res. 2010;1:297-301. doi: 10.4103/0110-5558.72420.

4 Baillargeon J, Urban RJ, Ottenbacher KJ, Pierson KS, Goodwin JS. Trends in Androgen Prescribing in the United States, 2001 to 2011. JAMA Intern Med. 2013;173(15):1465-1466. doi:10.1001/ jamainternmed.2013.6895

5 Jasuja GK, Bhasin S, Rose AJ. Patterns of testosterone prescription overuse. Curr Opin Endocrinol Diabetes Obes. 2017;24(3):240-245. doi:10.1097/ MED.0000000000000336

6 Baillargeon J, Kuo YF, Westra JR, Urban RJ, Goodwin JS. Testosterone Prescribing in the United States, 2002-2016. JAMA. 2018;320(2):200-202. doi:10.1001/ jama.2018.7999

7 Campbell JD, Milenkovic U, Usta MF, Albersen M, Bivalacqua TJ. The good, bad, and the ugly of regenerative therapies for erectile dysfunction. Transl Androl Urol. 2020;9(Suppl 2):S252-S261. doi:10.21037/tau.2019.10.06

8 Stevenson FA, Kerr C, Murray E, Nazareth I. Information from the Internet and the doctor-patient relationship: the patient perspective--a qualitative study. BMC Fam Pract. 2007;8:47. Published 2007 Aug 16. doi:10.1186/1471-2296-8-47

9 Eysenbach G, Köhler C. How do consumers search for and appraise health information on the world wide web? Qualitative study using focus groups, usability tests, and in-depth interviews. BMJ. 2002;324(7337):573-577. doi:10.1136/ bmj.324.7337.573

10 Zhou CK, Advani S, Chaloux M, et al. Trends and Patterns of Testosterone Therapy among U.S. Male Medicare Beneficiaries, 1999 to 2014. J Urol. 2020;203(6):1184-1190. doi:10.1097/ JU.0000000000000744
These three therapies are advertised on websites as treatments to increase libido and energy, but all these therapies lack both FDA-approval and stricter regulations. This is troublesome since consumers are increasing relying on the internet for their first source of health information, before physician consultation. ${ }^{8}$ Therefore, they might be inclined to believe that the treatments offered are standard of care and be misled regarding safety and efficacy.

There are several limitations to our study. Our study relied on internet search results, and as the internet is constantly changing, we may have missed some clinics that do not have a website or do not promote themselves visibly online. Also, it is possible that some websites may be outdated and do not accurately represent the provider or services offered at this time. Additionally, we confined our focus to our state to understand this microcosm which may not be generalizable to larger population centers across the U.S.

11 Mintzes B. The marketing of testosterone treatments for age-related low testosterone or 'Low T'. Curr Opin Endocrinol Diabetes Obes. 2018;25(3):224-230. doi:10.1097/MED.0000000000000412

12 Houman JJ, Eleswarapu SV, Mills JN. Current and future trends in men's health clinics. Transl Androl Urol. 2020;9(Suppl 2):S116-S122. doi:10.21037/ tau.2019.08.33

13 Saloner B, Cope LC, Hempstead K, Rhodes KV, Polsky D, Kenney GM. Price Transparency in Primary Care: Can Patients Learn About Costs When Scheduling an Appointment?. J Gen Intern Med. 2017;32(7):815-821. doi:10.1007/s11606-017-4003-4

14 Oberlin DT, Masson P, Brannigan RE. Testosterone replacement therapy and the internet: an assessment of providers' health-related web site information content. Urology. 2015;85(4):814-818. doi:10.1016/j. urology.2014.11.043

15 What is Low Testosterone? Low Testosterone: Symptoms, Diagnosis \& Treatment - Urology Care Foundation. https://www.urologyhealth.org/urologicconditions/low-testosterone. Accessed April 9, 2020.

16 Lokeshwar SD, Bitran J, Ramasamy R. Changes in testosterone prescribing patterns after FDA warning. Transl Androl Urol. 2019;8(Suppl 3):S287-S288. doi: 10.21037/tau.2019.04.03

17 SMSNA POSITION STATEMENT ON RESTORATIVE THERAPIES FOR ED. smsna.org. https://www.smsna.org/V1/news/433-smsna-positionstatement-on-restorative-therapies-for-ed. Published March 19, 2019. Accessed April 15, 2020.

\section{Conclusion}

Men with hypogonadal symptoms or erectile dysfunction continue to seek treatment wherever they can. Many clinics across the country now serve these needs directly by marketing themselves as men's health clinics. In our local review of publicly available information, these men's clinics are mostly privately owned and offer cash-based services with minimal price transparency. Many offer therapies that either have minimal supporting evidence or are not FDA approved. While many men may benefit from these therapies, they must be educated and also understand any risks that accompany these non-FDA approved treatments offered by providers without a comprehensive review of their entire health profile.

https://doi.org/10.32873/unmc.dc.gmerj.2.2.004 